Disponível em:

http://editora.unoesc.edu.br/index.php/race

Race, Joaçaba, v. 14, n. 3, p. 1091-1118, set./dez. 2015

\title{
APRENDIZAGEM ORGANIZACIONAL NO SETOR FARMACÊUTICO: UMA ANÁLISE MULTINÍVEL A PARTIR DA PERCEPÇÃO DOS GESTORES
}

\section{Organizational learning in the pharmaceutical industry: a multilevel analysis from the managers' perception}

Elen Cristina Albuquerque da Silva

E-mail: albuquerqueelen@gmail.com

Mestre e graduada em Administração pela Universidade Metodista de São Paulo.

\begin{abstract}
Almir Martins Vieira
E-mail: almir.vieira@gmail.com

Doutor em Educação pela Universidade Estadual Paulista; Mestre em Administração pela Universidade Metodista de São Paulo; Coordenador do Programa de Pós-Graduação (Mestrado) em Administração da Universidade Metodista de São Paulo. Endereço para contato: Rua do Sacramento, 230, Rudge Ramos, 09640-000, São Bernardo do Campo, São Paulo, Brasil.

Edson Keyso de Miranda Kubo

E-mail: edsonkubo@uscs.edu.br

Doutor em Administração pela Fundação Getúlio Vargas; Mestre em Administração pela Kobe University, Japão; Professor do programa de pós-graduação em Administração da Universidade Municipal de São Caetano do Sul.

Marcelo de Souza Bispo

E-mail:marcelodesouzabispo@gmail.com

Doutor em Administração pela Universidade Presbiteriana Mackenzie; pós-doutorando na área de Sociologia na Universidade de Kentucky, EUA; Professor do programa de pós-graduação em Administração da Universidade Federal da Paraíba.
\end{abstract}

Artigo recebido em 24 de setembro de 2014. Aceito em 30 de junho de 2015. 
Resumo

Neste trabalho se teve o objetivo de compreender como ocorre o desenvolvimento da aprendizagem nos níveis individual, grupal e organizacional, a partir da percepção dos gestores de uma empresa do setor Farmacêutico. Para tanto, assumiu-se uma abordagem qualitativa, tomando a entrevista semiestruturada enquanto instrumento para a coleta de dados. As entrevistas foram realizadas com os gestores da empresa pesquisada. Como principais resultados, constatou-se que a aprendizagem, em múltiplos níveis (individual, grupal e organizacional), ocorre por vários meios na indústria farmacêutica, manifestandose enquanto formas de compartilhamento que se configuram como fundamentais para a competitividade da organização.

Palavras-chave: Aprendizagem organizacional. Aprendizagem individual. Aprendizagem grupal.

\section{Organizational learning in the pharmaceutical industry: a multilevel analysis from the managers' perception}

Abstract

In the following study, the aim was to understand how the development of the learning in individual, group and organizational levels happen, from the perceptions of managers from a pharmaceutical industry. For this purpose, a qualitative approach was assumed, taking the semi-structured interview as the instrument for data collection. The interviews were held with the managers of the searched industry. As main results, it was found that learning, in multiple levels (individual, group and organizational), happens through various means in the pharmaceutical industry, expressing itself as forms of sharing that are configured as fundamental for the competitiveness of the company.

Keywords: Organizational learning. Individual learning. Group learning.

\section{INTRODUÇÃO}

No contexto mercadológico, a gestão do conhecimento e a inovação são elementos fundamentais para a competitividade organizacional. No cenário atual, no qual estão inseridas organizações públicas e privadas, vigora uma realidade dinâmica de padrão altamente competitivo, no qual a mudança e a inovação exercem papel decisivo para a obtenção do sucesso organizacional. Nesse universo, a aprendizagem é tratada como um processo estratégico essencial para que as organizações desenvolvam suas competências para atuar nesse ambiente cada vez mais mutável (FIOL; LYLES, 1985; CHOO, 2006; TAKAHASHI; FISCHER, 2010; FLASCHBERGER; GUGGLBERGER; DIETSCHER, 2013). 
Atualmente, as organizações empresariais utilizam diversas ferramentas e abordagens para administrar o processo de desenvolvimento de pessoas, isto é, estão preocupadas com os novos desafios a serem enfrentados diariamente. Por isso da importância desse processo como um meio para enfrentar o combate diário de sobrevivência organizacional. A aprendizagem continuada faz parte do desenvolvimento de pessoas no contexto organizacional e tem inegável importância para as organizações e seus colaboradores (ARGYRIS; SCHON, 1996; AMARO, 2014; NOGUEIRA; ODELIUS, 2015), de forma que ambos busquem alcançar a competitividade pelo aprendizado contínuo, como forma de se manterem atualizados e preparados para os impactos das mudanças no meio social e no meio tecnológico.

Com base nesse contexto, neste estudo assumiu-se como objetivo geral compreender como se manifesta o desenvolvimento da aprendizagem nos níveis individual, grupal e organizacional, a partir da percepção dos gestores de uma empresa do setor Farmacêutico. O estudo, de caráter qualitativo, foi conduzido por meio de entrevistas semiestruturadas. A escolha da indústria farmacêutica ocorreu em razão da dinamicidade desse setor e da demanda intensa por inovação (POWELL, 1998). Assim, os temas aprendizagem e conhecimento apresentam-se relevantes para a compreensão dos processos inovadores do setor, como também da estrutura de competitividades das empresas (WEICK; WESTLEY, 2004). Ou seja, assume-se que a aprendizagem organizacional diz respeito à forma pela qual as organizações adquirem conhecimento e ganham experiência, uma vez que tal conhecimento exerce influência sobre o seu desempenho (DODGSON, 1993; CHOO, 2006).

Para tanto, este trabalho apresenta, além desta introdução, uma breve discussão teórica, seguida dos procedimentos metodológicos da pesquisa. $\mathrm{Na}$ sequência, à luz do referencial teórico assumido, são apresentados e discutidos os resultados e algumas considerações finais, bem como propostas para futuras pesquisas relacionadas ao tema.

\section{REFERENCIAL TEÓRICO}

\subsection{APRENDIZAGEM NAS ORGANIZAÇÕES E SEUS NÍVEIS DE ANÁLISE}

A aprendizagem nas organizações pode ser observada como processo ou como resultado (RUAS; ANTONELLO, 2003; ANTONELLO; GODOY, 
2010; NOGUEIRA; ODELIUS, 2015), para tanto, o conhecimento acumulado e a informação são extremamente relevantes para esse processo. De acordo com Caldeira e Godoy (2012), a aprendizagem organizacional tem sido estudada a partir de seu caráter multidisciplinar, que a torna alvo de estudos sob diferentes enfoques: psicológico, sociológico, antropológico, político, histórico e econômico. Diversos autores tratam a aprendizagem nas organizações como um fenômeno multinível, ou seja, pode ser analisadas pelas perspectivas individual, grupal, organizacional e interorganizacional (DODGSON, 1993; CROSSAN; LANE; WHITE, 1999; DEFILLIPPI; ORNSTEIN, 2003; FLASCHBERGER; GUGGLBERGER; DIETSCHER, 2013; BIDO et al., 2010; MOZZATO; BITENCOURT, 2014).

Para Kim (1993), a aprendizagem individual ocorre por meio de um ciclo, isto é, o indivíduo recebe um dado novo, assimila, reflete com base em experiências anteriores, chega a conclusões sobre tal informação e a armazena em forma de modelo mental. O autor afirma que esse ciclo ocorre por modificações e processos de acordo com as crenças no modelo mental de cada indivíduo. Assim, o ciclo afeta a aprendizagem organizacional a partir de influências nos modelos mentais que são compartilhados em suas rotinas, memórias e procedimentos, orientando o processo de tomada de decisões em nível organizacional, ou seja, ocorre a transferência do aprendizado organizacional.

Segundo Maier, Prange e Rosenstiel (2001), um grupo tem a capacidade muito maior de armazenar conhecimento do que um indivíduo, isso porque o grupo tem o somatório de conhecimento armazenado por cada indivíduo. Essa proposição é convergente com o que Huber (1991) chama de memória organizacional, isto é, os indivíduos compartilham seus conhecimentos entre si, gerando o conhecimento do grupo, que é disseminado na organização.

Kim (1993) afirma que a organização somente aprende por meio de seus colaboradores. Porém, não depende de um ser específico: isso porque os indivíduos se unem como equipes de trabalho, departamentos, projetos, etc. Mesmo que cada membro tenha uma passagem temporária, durante a trajetória, cada indivíduo deixa sua marca ou seu legado de aprendizagem na organização. Nesse contexto, a influência exercida pelo indivíduo ou pelo grupo exerce papel crucial no compartilhamento do modelo mental individual. Isso indica que tanto gestores quanto grupos são muito influentes, considerando-se o poder que detêm. Contudo, um grupo numeroso de colaboradores unidos também exerce influência nesses modelos mentais, mas vale ressaltar que a forma como cada organização tem a visão de mundo é reflexo de sua cultura, artefatos e regras (FIOL; LYLES, 1985; DAFT; WEICK, 2007). 
Assim, a organização desenvolve novos princípios, gerando a aprendizagem, fenômeno que Visser (2003) chama de comportamento adaptativo. Atualmente, muitas empresas já perceberam que a aprendizagem organizacional pode ser trabalhada com seus funcionários para trazer vantagem competitiva em relação aos seus concorrentes, como estratégia para buscar novas práticas organizacionais, estimulando o desenvolvimento da aprendizagem e das competências de seus funcionários, “[...] tornando este fenômeno um ciclo para a mudança organizacional." (VISSER, 2003, p. 272).

Para Eboli (2004) e Moscardini e Klein (2015), o conhecimento é fonte de vantagem competitiva para as empresas que visam a um desenvolvimento sustentável. Para as autoras, gerar e transferir conhecimento na empresa é sempre um processo de aprendizagem organizacional: para se obter sucesso na convergência entre o desenvolvimento de talentos e as estratégias do negócio, um projeto de educação corporativa deve identificar, formar e mobilizar as competências críticas, no sentido de agregar valor ao negócio e, assim, aumentar a competitividade.

A aprendizagem organizacional busca aumentar a capacidade da empresa em ações de melhoria e desempenho. Conforme Kim (1993), Pawlowsky (2001) e Brusoni e Rosenkranz (2014), esse fluxo ocorre pelo processamento de informações e pela aquisição de novos conhecimentos pelos indivíduos e posterior compartilhamento no âmbito do grupo, gerando a disseminação pela organização.

Ou seja, as organizações são manifestações oriundas das ações individuais e coletivas de seus membros, resultando em uma identidade coletiva fruto da ação de seus atores sociais, conforme destacam Bispo e Mello (2012). Assim, a aprendizagem é fonte de heterogeneidade entre organizações, podendo tornar-se vantagem competitiva.

\section{PROCEDIMENTOS METODOLÓGICOS}

Neste estudo, optou-se pela pesquisa qualitativa, que busca a compreensão do significado que os indivíduos constroem com base em suas experiências e sobre o mundo, sem se preocupar com o que poderá ocorrer no futuro, mas buscando compreender o significado de estar em determinado ambiente. Segundo Merrian (1998), a pesquisa qualitativa foca o nível social com o objetivo de interpretar as

intenções e significados, de acordo com a visão da realidade que é construída pela interação dos indivíduos na sociedade. A escolha desse método se justifica pelo que 
definem Caldeira e Godoy (2012), ao apresentarem a aprendizagem organizacional como um fenômeno construído socialmente, a partir de processos de interpretação e processamento de informações.

A escolha da empresa do setor Farmacêutico aconteceu pelo fato de ela ter característica única, isto é, ser pioneira na fabricação de alguns medicamentos, sendo uma organização que preza por inovação em seu segmento, participando de um mercado volátil e diante de grandes concorrentes nacionais e multinacionais. A organização na qual trabalham os participantes se trata de uma indústria farmacêutica localizada na região do Grande ABC paulista, com atuação em todo o território nacional, atendendo mensalmente acerca 50.000 médicos por meio de sua equipe de propagandistas. É uma empresa de médio porte, que surgiu em 1984, empregando atualmente 200 funcionários, além de prestadores de serviços; tem como clientes pessoas físicas e empresas públicas e privadas.

Os dados foram coletados por meio de entrevistas semiestruturadas, baseadas em roteiro prévio elaborado sem apego à rigidez, conforme indica Vergara (2009). Tal postura permitiu incluir, à medida que aconteciam as entrevistas, questões complementares para a investigação da temática. O agendamento das entrevistas e a escolha do local tomaram por base a disponibilidade dos entrevistados, os quais, em sua totalidade, autorizaram a gravação das entrevistas, fato que permitiu a transcrição do material, viabilizando análise mais cuidadosa dos dados. As entrevistas levaram um tempo de duas horas, em média, sendo realizadas de 22 de outubro a 17 de novembro de 2013.

Baseando-se em Denzin e Lincoln (2006, p. 127), a postura de "triangulação" veio à tona, quando se misturaram, inverteram ou exploraram os diferentes tipos de dados oriundos das narrativas das entrevistas. Buscou-se, assim, utilizar o mesmo rigor do estudo de caso para esta pesquisa, aprofundando-se na análise das relações convergentes e divergentes dos dados obtidos. Procedeu-se, também, à codificação dos dados, para atribuir uma designação aos conceitos relevantes encontrados na transcrição das entrevistas e registros de campo. Graças a esse procedimento, foi possível validar as subcategorias e dimensões ou categorias de análise (GIL, 2010).

Participaram da pesquisa profissionais pertencentes ao nível gerencial da organização, composto por seis gestores: gerente de produção (53 anos de idade, cinco de organização), gerente de PCP (43 anos, seis de organização), gerente de treinamento (53 anos, quatro de organização), gerente técnico (62 anos, 11 de organização), gerente de controle de qualidade (34 anos, um de organização) e gerente de desenvolvimento farmacotécnico (37 anos, cinco de organização). 
É válido apontar que todos relataram experiência anterior de gerência em outras organizações do mesmo segmento.

Para sistematizar os dados coletados, foram realizados os seguintes procedimentos: transcrição das entrevistas, leitura das entrevistas, comparação das entrevistas entre si, análise dos pontos comuns no grupo, extração dos posicionamentos nas entrevistas e análise interpretativa das entrevistas.

\section{ANÁLISE E DISCUSSÃO DOS RESULTADOS}

A partir das entrevistas, verificou-se como ocorre o desenvolvimento da aprendizagem organizacional, assim como aprendizagem individual e grupal colaboram e se relacionam para esse processo na empresa. Para tanto, trabalhou-se com as três dimensões da aprendizagem (individual-AI; grupal-AG; organizacional - AO), a partir das quais foram criadas três subcategorias, sendo: AO (processo, resultado e mudanças), AI (formação e relação com a aprendizagem organizacional) e AG (capacidade e intercâmbio).

\subsection{APRENDIZAGEM ORGANIZACIONAL: PROCESSO, RESULTADO E MUDANÇAS}

Alguns autores conceituam o fenômeno da aprendizagem tanto como um processo quanto como um resultado, pois se trata de um fenômeno constante e cíclico, isto é, contínuo, que não tem fim. Para que as organizações se mantenham no mercado, atendendo às demandas internas e externas de forma competitiva, é preciso buscar atualização e novidades constantemente, uma vez que o segmento farmacêutico é exigente e muito competitivo. Essa mudança pode ocorrer no contexto como um todo, ou pode ser uma adaptação, uma flexibilização, como novidades em procedimentos, rotinas, processos, etc. Nesse sentido, todos os fatores levam ao ato de mudar, ou seja, a aprendizagem exige o ato de buscar algo novo, melhor.

Diante desse contexto, o Entrevistado 1, quando questionado sobre quais ocasiões evidenciam a aprendizagem dele próprio e da equipe, aponta que a aprendizagem ocorre o tempo todo. $\mathrm{Na}$ condição de gestor, afirma “[...] perceber a aprendizagem da equipe", por exemplo, quando um funcionário já consegue executar todas as atividades elencadas para determinada função e está disponível para assumir novas tarefas (responsabilidade) ou talvez uma nova função. A organização 
vê a necessidade ou a possibilidade de esse indivíduo exercer " $[\ldots]$ atividades que exigem mais do indivíduo", porque "[...] é capaz de exercer outras tarefas que exigem maior nível de complexidade.” (informações verbais).

De acordo com o Entrevistado 6, essa perspectiva também se confirma, conforme aponta:

\begin{abstract}
Quando dialogamos e resolvemos os problemas em conjunto, as experiências são compartilhadas. Com certeza, as experiências podem nos ajudar a ter uma visão diferente de algo que não pensávamos em determinado momento/processo. A união da equipe em busca de crescimento do grupo e não apenas de uma pessoa, a experiência em cursos e treinamentos traz crescimento para toda a equipe, um retorno pós-investimento em treinamento, cursos internos e externos. É, eu acho importante que ocorra também a abertura para execução, e no caso da minha equipe, isso ocorre com frequência. (informação verbal).
\end{abstract}

Considerando ainda a visão da aprendizagem como o processo apresentado, é possível compartilhar a visão como um resultado, pois o gestor consegue perceber a aprendizagem por meio dos resultados, isto é, suas atividades são desenvolvidas de forma correta, como se esperava, gerando resultados positivos. Assim, as organizações tratam a aprendizagem como um processo estratégico essencial para que desenvolvam suas competências para atuarem nesse ambiente cada vez mais mutável (TAKAHASHI; FISCHER, 2010; CROSSAN; LANE; WHITE, 1999).

Ressalta-se que não basta ter as informações: é preciso que estas gerem uma ação com base nos dados existentes, criando, assim, um repositório de conhecimento na organização, que deve ser compartilhado com os indivíduos e grupos da empresa, de modo a desenvolver a aprendizagem organizacional, conforme apontam Ruas e Antonello (2003), ao tratarem do conhecimento acumulado na organização. Um dos gestores sinaliza algo semelhante a esse contexto:

\footnotetext{
Alguns fatores para contribuir nessa aprendizagem [...] a questão do funcionário, digamos, correr atrás das informações [...] as informações chegam até mim também, de forma clara e concreta, para que a gente possa avaliar num todo, no geral. Então eu acho que são alguns fatores que demonstram para mim que eles estão assimilando e estão aprendendo. (informação verbal).
} 
Dessa forma, percebe-se que o processo da aprendizagem exige uma ação de busca relacionada à mudança. No caso relatado pelo entrevistado, a mudança já se inicia com a atitude de buscar a informação para subsidiar o gestor, com posterior impacto no resultado organizacional.

A organização pesquisada promove alguns treinamentos específicos para a equipe de vendas, buscando a interação entre os indivíduos e o compartilhamento de informação e conhecimento. O compartilhamento e as ações que serão tomadas fazem com que a equipe e a organização participem ativamente da aprendizagem organizacional. Nesse contexto, é válida também a proposição de Bispo e Mello (2012), quando apontam que, por mais que as pessoas busquem criar modelos de organizações estáveis e com limites físicos, as organizações sempre são resultado das interações cotidianas e da intersubjetividade criada entre seus membros, a partir de suas práticas.

Alguns autores tratam também a aprendizagem organizacional como um fator relacionado à solução de problemas. Assim, o Entrevistado 4 aborda a seguinte situação:

Dependendo do caso, os problemas são discutidos em grupo
[...] por exemplo, surgiu um problema numa área de produ-
ção. Esse problema é da área de produção, mas vai interferir
em toda empresa, quais são as áreas que estão ligadas com esse
problema ocorrido? Então tem que verificar quais são as áreas,
juntar as pessoas e discutir isso, né? Um grupo. Se, de repente,
ocorreu um problema que é específico da área, por exemplo,
eu posso discutir em grupo. (informação verbal).

Nesse sentido, a fala do Entrevistado 4 é convergente: “[...] quando eu percebo que a pessoa entendeu aquela mensagem, daquilo que ele precisa fazer. Se ele entendeu, tirou as dúvidas, ele vai conseguir praticar." (informação verbal).

Ainda, quando esse Entrevistado diz: “[...] então você percebe quando a pessoa não faz corretamente, e aí existe um trabalho corretivo pra ele" (informação verbal). O relato corrobora com o pensamento de Ruas e Antonello (2003), segundo o qual, a aprendizagem organizacional é um processo por meio do qual os colaboradores detectam erros ou desvios e os corrigem, reestruturando, assim, a teoria em uso da organização, esta entendida como uma mudança que ocorre nas rotinas defensivas que fazem parte das organizações. Isso se confirma também na fala do Entrevistado 6, quando relata: 
Quando a gente quer fazer alguma mudança no processo, ou de algum procedimento, sempre procuro planejar, porque mesmo o planejado pode sofrer imprevistos. Então, eu e minha equipe procuramos planejar sempre, pois assim conseguimos identificar o que pode dar errado e muito certo, podemos corrigir esse erro mesmo antes da mudança ocorrer efetivamente. Acho que isso, quando planejamos, temos mais chance de fazer a coisa dar certo. (informação verbal).

Ao tomarmos a aprendizagem enquanto processo, envolvendo criação, difusão, integração do conhecimento e ações práticas, é notável que a troca de informações é elemento essencial, não somente para a $\mathrm{AO}$, mas também para a aprendizagem individual (AI), que ocorre por meio de um ciclo. Isto é, o indivíduo recebe um dado novo, assimila, reflete com base em experiências anteriores, chega a conclusões sobre tal informação e armazena em forma de modelo mental (KIM, 1993).

Esse fluxo é importante para que ocorra a AO, ou seja, a AI contribui para que, de fato, ocorra a aprendizagem organizacional, uma vez que é necessário o compartilhamento de informações, ideias e conhecimentos, assumindo, assim, o ciclo do processo, e então colocá-lo em prática, de forma que seja possível chegar às devidas conclusões, auxiliando nos processos de decisão. Esse intercâmbio faz parte do processo da aprendizagem organizacional. Diante desse contexto, o Entrevistado 2 confirma que o fator que contribui para aprendizagem é a comunicação, visto que uma mensagem/informação pode ser interpretada de diferentes formas. Ou seja, quando ele fala em comunicação, entende-se o intercâmbio, uma vez que Kim (1993) e Pawlowsky (2001) apontam quatro passos que ocorrem no processo da AO. Entretanto, esses passos não precisam ser necessariamente sequenciais:

a) identificação da informação (que seja importante para a criação do conhecimento e/ou aprendizagem);

b) troca e difusão do conhecimento (no nível individual ou coletivo);

c) integração do conhecimento nos sistemas já existentes (no nível individual ou coletivo);

d) transformação do novo conhecimento em ação (aplicação prática nas rotinas, ocasionando impacto no comportamento organizacional). 


\subsection{APRENDIZAGEM INDIVIDUAL: FORMAÇÃO E RELAÇÃO COM A APRENDIZAGEM ORGANIZACIONAL}

Kim (1993) defende que o processo da AO ocorre por modificações e processos, de acordo com as crenças no modelo mental de cada indivíduo. Assim, o ciclo afeta a aprendizagem organizacional a partir de influências nos modelos mentais que são compartilhados em suas rotinas, memórias e procedimentos, orientando o processo de tomada de decisões no nível organizacional, ou seja, ocorre a transferência do aprendizado organizacional. Tal proposição converge com a fala do Entrevistado 1:

Acredito que o que contribui muito para o aprendizagem no trabalho é mesmo o histórico né, é o que vai acontecendo no dia a dia, é o que você vai conseguindo pegar [...] no nosso caso, produtos, são produtos farmacêuticos [...] então vai acontecendo [...] a cada lote do produto que você faz, e se alguma coisa sai daquilo que acontece com o produto, o que deixou de acontecer [...] essa percepção de sempre ter a mesma rotina $[. .$.$] sempre acontecer a mesma coisa [. .$.$] e saber se$ em algum ponto essa rotina é quebrada $[. .$.$] o que vai aconte-$ cer depois disso. (informação verbal).

Dessa forma, percebe-se a memória organizacional, que se forma com o conhecimento explícito e implícito que envolve os níveis individuais e grupais, e estes são extremamente importantes para que a organização tome decisões e ações no contexto atual, gerando a transferência do conhecimento para dias atuais e, se necessário, adaptando-a a uma nova realidade ou rotina.

$\mathrm{O}$ ciclo da aprendizagem individual afeta a $\mathrm{AO}$, orientando o processo de tomada de decisão (transferência). De acordo com Crossan, Lane e White (1999) e Nogueira e Odelius (2015), os processos da aprendizagem valorizam a mudança contínua nas organizações e também a união de diferentes níveis de análise: individual, grupal e organizacional. O Entrevistado 3 diz:

Os fatores que contribuem para a aprendizagem são principalmente a troca de experiência, pois se você tem uma ideia para atingir um objetivo e a pessoa que você está explicando isso, ela tem outra ideia e você mudar o caminho, eu acho que é uma forma que você consegue contribuir para que o aprendizado seja das duas partes. Essa troca de experiência, eu acho 
que é fundamental. E pode até ser de uma coisa que já vinha sendo desenvolvida de certa forma, no momento que existe essa troca de informação, pode mudar. (informação verbal).

De acordo com essa fala, depreende-se que, por meio do intercâmbio de informações e conhecimento, existe claramente a aprendizagem, mesmo no nível individual, pois a pessoa começa a visualizar outra forma de pensar ou executar determinada atividade que até então não havia feito. Ou seja, existe a aquisição da nova informação e sua difusão entre as partes (discussões), chegando-se, então, à integração do conhecimento e, por fim, às ações que vão colocá-la em prática, e estas podem gerar mudanças que, de fato, são essenciais para que ocorra o processo de aprendizagem. Diante disso, é importante que tanto o indivíduo quanto o grupo e as organizações percebam que é necessário estar aberto e aceitar mudanças. Assim como defendem Argyris e Schon (1996), para as organizações responderem às mudanças, é necessário aprender continuamente, ou seja, existe uma relação entre aprender e mudar.

Alguns autores afirmam que a organização somente aprende por meio de seus colaboradores, sem depender de um ser específico, isso porque os indivíduos se unem como equipes de trabalho, departamentos, etc. Tal afirmação é convergente com a fala dos entrevistados $1,3,4,5$ e 6, pois estes afirmam que a participação dos funcionários é essencial na construção da aprendizagem organizacional.

Quando o Entrevistado 1 diz: “[...] todas as decisões são tomadas em conjunto, pelo analista responsável pela situação e pelo supervisor, acompanhados por mim. Essa é uma regra geral", o nível individual fica claro quando ele cita "o analista" ou "o supervisor", porém, sem determinar uma pessoa específica: para que funcione bem e se tomem decisões, é necessário o trabalho em grupo, isto é, da equipe.

\subsection{APRENDIZAGEM GRUPAL: CAPACIDADE E INTERCÂMBIO}

Autores como Huber (1991) e Maier, Prange e Rosenstiel (2001) abordam a importância do grupo na aprendizagem organizacional, pois o grupo tem capacidade para armazenar conhecimento, uma vez que engloba o conhecimento armazenado por cada indivíduo. A importância do grupo também fica explícita na fala dos 
entrevistados, por exemplo, quando o Entrevistado 1 fala que é regra geral o trabalho em equipe, bem como a tomada de decisão:

\footnotetext{
É regra geral a tomada de decisão junto à equipe. Às vezes, a gente envolve os outros também da equipe quando a gente acha ou percebe algum item que vai ser importante para os outros. Também, mesmo que eles não estejam a par daquele projeto, mas que vai ser importante para eles aprenderem [...] isso com o projeto deles também a gente acaba envolvendo todo mundo. (informação verbal).
}

O Entrevistado 2 afirma que, quando as decisões e reflexões são discutidas em grupo (pela equipe), é possível ter uma visão holística, facilitando o processo de aprendizagem: “[...] elas são discutidas em grupo. Porque eu acabo aprendendo também a ter uma visão completa, aí não existem informações que eu desconheça. Em grupo mesmo.” (informação verbal). Diante dessas afirmações, percebe-se que algumas decisões são tomadas em torno da própria experiência dos funcionários. Outro ponto importante tratado por alguns autores é a memória organizacional (KIM, 1993), isto é, os indivíduos compartilham seus conhecimentos entre si, gerando o conhecimento do grupo que é disseminado na organização. Essa prática foi notada na afirmação do Entrevistado 3: "Você tem uma ideia, vê o que pode ser melhorado nessa ideia e passa para a equipe. Com a equipe acatando e colocando em prática, a gente nota que o pensado está correto. Caso contrário, a gente faz as correções, se for consenso." (informação verbal).

Diante dessa situação, nota-se que, além da importância do grupo e do compartilhamento da equipe, a organização e a gestão cedem espaço para que ocorra a aprendizagem grupal, uma vez que se tem clareza que este trabalho em grupo surtirá um efeito positivo para o crescimento da equipe e melhorias em sua área, e principalmente para a organização como um todo, pois trará influências no resultado final.

As pessoas têm papel fundamental nas organizações, pois suas atividades desempenhadas com mais competência geram vantagem competitiva às empresas. Isso inclui conhecimentos, qualificações e habilidades incorporadas nos funcionários, ou seja, conhecimentos integrados dentro de uma empresa que a distinguem de suas concorrentes e agregam valor para os clientes. A esse respeito, o Entrevistado 3 traz algumas situações decorrentes da rotina de sua área: 
Acho que a troca de experiências é fundamental. E, nesse caso, uma experiência de uma pessoa que está o dia todo no campo, com uma que já passou pelo campo, mas hoje já não está mais [...] pode acontecer porque existe esse choque, hoje a visão é uma [...] talvez dois anos antes não fosse assim. Então a gente corrige, se for necessário. (informação verbal).

O ponto de vista apresentado pelo Entrevistado 3 se relaciona ao que Choo (2006) defende como aprendizagem de circuito único e de circuito duplo, quando as normas organizacionais ocorrem de forma cíclica. Para o circuito duplo ocorrer, é necessário que seja detectado e corrigido algum problema/erro, pois gera modificação nas normas e políticas organizacionais, isto é, além de resolver um problema, é também identificada a forma de evitá-lo. Este estudo tem convergência com a proposta de Argyris (1999) e Amaro (2014), pois faz com que os colaboradores aprendam a lidar com os problemas, além de auxiliar a entender como as pessoas pensam e suas razões e regras cognitivas para a ação.

Diante desse contexto, é perceptível a proposição de Pawlowsky (2001), Antonello e Godoy (2010) e Nogueira e Odelius (2015), ao defenderem que a aprendizagem organizacional deve ser entendida como distinta da aprendizagem individual, destacando-se o nível grupal, pois este funciona como porta de entrada para a aprendizagem organizacional. Porém, todos os níveis estão interligados e devem sempre ser considerados quando se trata do fenômeno (evento observável/ experimentação) da aprendizagem. Isso foi comprovado nas entrevistas, pois na fala de todos os entrevistados a palavra "equipe" é comum e é tratada como de grande importância para o sucesso das tarefas realizadas na busca do objetivo comum do departamento e da empresa como um todo. Foi possível visualizar isso em todos os entrevistados. Observa-se tal situação na fala do Entrevistado 1:

Gosto de fazer isso bastante, que eles interajam bastante com todas as outras áreas, e é óbvio que assim os projetos são debatidos em reuniões mais gerenciais e nós levamos isso para os funcionários. Mas existem alguns casos que eu levo comigo o supervisor ou o analista para uma reunião pra que ele que tá realmente fazendo, ele que tá pondo a mão na massa, às vezes ele tem uma visão um pouco diferente de nós. (informação verbal). 
Assim, o entrevistado deixa claro que as decisões e definições de processos ou procedimentos, rotinas e atividades são sempre tomadas em grupo, seja pelo grupo mais gerencial, dependendo da situação, seja pelas pessoas que estão diretamente envolvidas, pois estas podem ter uma visão diferenciada do grupo gerencial, que nem sempre executa atividades operacionais. E ainda, nessa fala, constata-se a importância de se ter uma visão diferente dos demais, fato que possibilita novas maneiras de pensar (com influência na tomada de decisão), pois poderá surgir algo novo que, até então, não havia sido pensado.

O Entrevistado 6 evidencia o trabalho em grupo como essencial para o sucesso da área e também da empresa, pois quando o trabalho em grupo, bem como a interação e compartilhamento do conhecimento existem, os objetivos organizacionais podem ser atingidos com mais rapidez e melhores resultados. Conforme o trabalho de Pawlowsky (2001) e Amaro (2014), os grupos são como sistemas sociais que ocorrem por suas dinâmicas, gerando a aprendizagem no interior das organizações, sendo estas como entidades que aprendem.

Quando trabalhamos em grupo, reunidos para a busca do melhor, sempre abertos a novidades, buscando a redução dos custos, a busca por qualidade, eficiência e lucro. Vejo que quando trabalhamos em grupo, as coisas fluem melhor, com mais rapidez, mais companheirismo, sem privilegiar ninguém, pensando na área como um todo, buscando o melhor para atingir os objetivos organizacionais. (informação verbal).

Nesse contexto, percebe-se que, de acordo com Bispo e Mello (2012, p. 734),

[...] a relação entre organização e aprendizagem está presente no processo de constituição e ação organizacional, no qual a aprendizagem é elemento essencial para que seja possível o "organizar coletivo", de modo que o resultado da organização, assim como da sua identidade, está relacionado ao aprender constante de um grupo.

Vale ressaltar que a aprendizagem deve ser algo que constitui a empresa, e não um mero discurso. Nesse sentido, o Entrevistado 4 aponta que a interação entre os níveis ocorre o tempo todo:

Se for um projeto de alta gestão, você mantém o alto nível, se é um projeto que envolve a parte operacional, você tem que discutir isso com eles [...] a sugestão deles é extremamente importante porque, às vezes, pode influenciar no projeto. Nós 
estamos com um cronograma de dois projetos grandes aqui, nós temos que unir pessoal [...] fizeram reuniões em grupo [...] o cronograma desse projeto não envolve a parte operacional $[. .$.$] envolve uma área técnica, mas ele é discutido. É$ discutido quem vai executar o projeto, com os executores [...] com todos nós que somos a empresa [...] que vamos receber o projeto [...] você detalha tudo e daqui a pouquinho tem que discutir tudo de novo, porque apareceram imprevistos e você vai mantendo esse intercâmbio continuamente. (informação verbal).

Diante disso, é possível compreender a importância do intercâmbio e como este influencia a capacidade da organização em sustentar alocações coordenadas de recursos, a fim de ajudar a empresa a atingir os seus objetivos. E ainda como ocorre a relação entre o intercâmbio e o aprendizado coletivo na organização, especialmente como coordenar as diversas habilidades de produção e integrar as múltiplas correntes de tecnologia. Ou seja, essa gestão de competências é essencial para administrar o grupo na busca pelos objetivos organizacionais.

A aprendizagem organizacional, conforme Pawlowsky (2001) e Moscardini e Klein (2015), é o aumento da capacidade da empresa em apresentar ações efetivas para manter ou melhorar o desempenho com base na experiência, proposição constatada pela fala do Entrevistado 4:

O funcionário trabalha, a gente acompanha o trabalho dele [...] se ele não estiver de acordo, não estiver fazendo corretamente aquilo, espera um pouquinho, assim vamos fazer melhor, vamos dar um jeito de fazer dessa forma diferente, quer dizer, você tem que dar um feedback, ou como incentivo para saber que fez bem feito, você tem que dar um elogio "parabéns, muito bem", isso dá uma motivação pra ele. E se eu falar pra ele o que ele fez errado, desmotiva, então tem que orientar ele, esse feedback [...] no sentido que ele também não seja ofendido com isso, mas que seja orientado, né? (informação verbal).

A experiência individual significa para esse Entrevistado que a participação ativa do gestor com o funcionário e a equipe é extremamente importante na construção do aprendizado, principalmente no sentido de que este seja visto como orientação, um ato de construção e melhoria e não como uma crítica ofensiva. Assim, a forma de tratar e conduzir as situações deve ser de natureza construtiva, tomando cuidado com as questões políticas, de conflitos e poder, que influenciam as organizações de aprendizagem. 
Conforme apontam alguns autores, existem fatores facilitadores de aprendizagem (ANTONELLO; GODOY, 2010; SONAGLIO; GODOI; SILVA, 2013; DIAS; SAUAIA; YOSHIZAKI, 2013), sendo práticas, políticas e condições que potencializam a ocorrência da aprendizagem, por exemplo: fontes de informação, compartilhamento de visões e experiências, revisão de conceitos, feedback construtivo e oportuno e ambiente propício para novas ideias. Tais facilitadores fornecem incentivos para que a aprendizagem ocorra de forma mais intensa na organização.

Quando Choo (2006) afirma que a aprendizagem organizacional ocorre pelo diagnóstico de erros e anomalias, a correção promove uma reestruturação da teoria em uso. Quando a ação não corresponde ao resultado, surge a oportunidade para a aprendizagem. Nesse contexto, o Entrevistado 1 afirma que mudanças planejadas possibilitam a aprendizagem, porém, mesmo algo planejado pode sofrer imprevistos e necessitar de interferência, seja para a correção de alguma coisa errada, seja para alguma mudança para que ocorra o resultado esperado. Nesse panorama, o Entrevistado 2 relata um exemplo que ocorreu na empresa:

Nós fizemos uma alteração grande no sistema integrado que chama ERP [...] esse planejamento foi feito durante uns três, quatro meses [...] quando fomos implantar esse sistema, as coisas já tinham sido resolvidas antes. Então, na implantação, com planejamento, o gerenciamento ocorreu de forma muito satisfatória. (informação verbal).

A importância do planejamento no processo de mudanças e na aprendizagem organizacional também é percebida pelos Entrevistados 4 e 5. Assim, o Entrevistado 4 aponta que, mesmo quando se tem um planejamento, podem ocorrer imprevistos e estes também possibilitam aprendizagem:

Sempre as planejadas possibilitam a aprendizagem, embora às vezes o não planejado pode acontecer certo. Então sempre quando existe planejamento, uma empresa não vive sem o planejamento. Ela tem que saber o que vai comprar, o que vai produzir e o que vai vender. Planejamento tem que existir, na família tem que existir o planejamento. Tem que existir esse planejamento, mas às vezes acontecem coisas não planejadas que você tem que estar preparado [...] como suportar isso? Há imprevistos, você tem que planejar o imprevisto, você tem que ter um amadurecimento tal pra você superar esse imprevisto. Esses imprevistos são não só as mudanças planejadas, mas como os imprevistos também proporcionam esse ambiente pra aprendizagem do grupo e da organização [...] imprevistos 
de termos gerais, de comportamento, em termo de estruturas, em termo de ações, problemas no processo, em termo de equipamento, uma coisa geral, uma inspeção que você recebe quando você não está sabendo, né? De repente, chego quatro horas da tarde e vem uma inspeção aqui, vou falar e agora? Como é que faz? Não estou preparado [...] tem que estar preparado, tem que se virar com isso, então isso é imprevisto. (informação verbal).

Quanto à existência do ambiente favorável à criação e à sugestão de novas ideias, todos se manifestaram de forma semelhante, formal ou informalmente, exceto o Entrevistado 2, que apresentou alguns sinais de descontentamento com a empresa e, talvez por estar desmotivado, tem se mostrado pessimista quanto à organização.

Durante as entrevistas, notou-se também que a aprendizagem organizacional ocorre entre as diversas áreas da empresa, por meio de contatos diretos e indiretos. Pawlowsky (2001) sustenta que, para ocorrer a gestão da aprendizagem organizacional, é necessário considerar a aprendizagem em diversos níveis, modos, tipos e processos, como agentes integrados e inter-relacionados para conduzirem a aprendizagem organizacional. Nesse sentido, o Entrevistado 1 aponta a necessidade de identificar e buscar informações sobre algo que precise ou possa ser melhorado:

Sim, a gente está sempre em contato com as outras áreas e sempre acontece tanto da gente verificar alguma coisa que está dando certo numa área e pensar no que a gente poderia adaptar aquilo ou usar integralmente na nossa área para melhorar nosso fluxo, melhorar algum processo [...] e assim como também nossos controles que são usados por outras áreas [...] também quando eles acham que vai valer a pena. (informação verbal).

De acordo com esse contexto, o Entrevistado 4 também afirma a existência constante dessa troca de informações e conhecimento entre as áreas, conforme segue:

Olha, a gente sempre faz isso, por quê? Se não houver essa troca de informações, essa ligação com a empresa [...] nós fazemos isso com outras empresas! Nós temos dúvidas de algum processo produtivo, um processo de validação, sobre o meio ambiente, qualquer coisa, como você faz isso, como você faz? Você pode receber a gente pra verificar o sistema de calibração das balanças [...] como faz isso? Você pode? Posso? Então esse benchmarking tem que existir no sentido de inter- 
câmbio, porque pode ser que nós não estejamos fazendo correto, mas existe alguma outra coisa, alguma empresa fazendo um pouquinho melhor. Então eu posso tentar, puxo aqui o que eles estão incrementando e posso colocar aqui, entendeu? Então sempre existe a ligação entre as empresas, entre as pessoas [...] digamos para determinados colegas de outras empresas, por exemplo, mando um e-mail: como é que faz isso? Entendeu? Existem as associações de classe que a gente tem bastante contato, aí nós vamos nas reuniões [...] encontramos outras pessoas e trocamos um montão de ideias, informações [...] é assim que funciona. (informação verbal).

Assim, a aprendizagem organizacional ocorre pela junção de conhecimento, valores, comportamento, conforme apontam alguns autores (PAWLOWSKY, 2001; BIDO et al., 2010), isto é, não basta a compreensão de determinada atividade ou processo, é necessária a visão de novas propostas para a ação. O Entrevistado 5 aponta essa rotina dentro da empresa:

Hoje na empresa, assim como numa outra empresa que eu já trabalhei, são feitas reuniões com outros departamentos, ou seja, de repente eu tenho uma ideia que possa possibilitar uma melhoria, não só para o meu setor como para os outros, então isso realmente é feito. Então cada um expõe sua ideia, né? E, no final, chegamos num consenso. E a partir daí a gente segue o fluxo de trabalho. (informação verbal).

Vale ressaltar que esse Entrevistado aponta inclusive sua experiência em organizações anteriores, de forma que é possível imaginar que, como isso já fez parte de sua experiência e foi armazenado em seu modelo mental, ele compartilha tais conhecimentos em forma de ação prática na equipe que atua, como também com as demais áreas. A empresa, por sua vez, insere-se em sua "memória organizacional" como algo a ser usado em suas rotinas e até mesmo na tomada de decisão.

Constata-se que, na organização pesquisada, a aprendizagem pode ser identificada em três dimensões (AI, AG e AO), fato que evidencia sua característica complexa. Destaca-se, na dimensão individual, que o indivíduo não precisa necessariamente da organização para aprender, diferentemente da organização, que precisa de seus membros para tal, uma vez que os colaboradores são como agentes de aprendizagem quando compartilham seus modelos mentais com a empresa. Vale ressaltar que os indivíduos têm seu modelo mental em constante mutação, envolvendo sua visão de mundo, suas experiências e conhecimentos implícitos e explícitos. 
Na dimensão grupal, o grupo é elemento-chave para maior capacidade de aprendizagem, pois várias pessoas têm maior capacidade de armazenamento de conhecimento do que uma única pessoa, além de gerar a construção desse conhecimento por meio da troca e intercâmbio de informações, compartilhando também experiências e, ainda na dimensão organizacional, quando da união de indivíduo e grupos, buscando um trabalho em equipe, com capacidade de adquirir novos conhecimentos, compartilhá-los e gerar ações por meio dessa aprendizagem.

Determinada a diversidade, percebe-se também um elemento vital para a análise, que tem caráter interorganizacional. Trata-se de outro nível da aprendizagem, também chamado por alguns autores de networking. De acordo com Bido et al. (2010), isso acontece a partir de alianças e parcerias estratégicas, ou seja, pela troca entre diferentes organizações, de acordo com seus interesses. Aprofundando-se nas análises dos dados coletados, observou-se que as entrevistas em geral forneceram ideias ou códigos que em seu conjunto sintetizavam as dimensões e respectivas subcategorias da aprendizagem organizacional. Seria efetiva a apresentação desses códigos encontrados na análise qualitativa das entrevistas e sua associação com os achados da literatura, conforme mostra o Quadro 1.

Quadro 1 - Relação entre o referencial teórico e as entrevistas

\begin{tabular}{|c|c|c|}
\hline $\begin{array}{l}\text { Dimensões de } \\
\text { aprendizagem } \\
\text { ou categorias } \\
\text { de análise }\end{array}$ & Códigos que emergiram das entrevistas & Referenciais teóricos \\
\hline $\begin{array}{l}\text { Aprendizagem } \\
\text { organizacio- } \\
\text { nal: processo, } \\
\text { resultados e } \\
\text { mudanças }\end{array}$ & $\begin{array}{l}\text { Compartilhamento de experiências nas soluções de } \\
\text { problemas; busca incessante de informações críti- } \\
\text { cas; resolução de problemas em grupo; práticas de } \\
\text { planejamento. }\end{array}$ & $\begin{array}{l}\text { Takahashi e Fischer (2010); Cros- } \\
\text { san, Lane e White (1999); Ruas e } \\
\text { Antonello (2003); Bispo e Mello } \\
\text { (2012); Kim (1993); Eboli (2004). }\end{array}$ \\
\hline $\begin{array}{l}\text { Aprendizagem } \\
\text { individual: } \\
\text { formação e } \\
\text { relação com a } \\
\text { aprendizagem } \\
\text { organizacional }\end{array}$ & $\begin{array}{l}\text { Tentativa de quebrar a rotina e buscar a inovação } \\
\text { incremental; troca de experiências. }\end{array}$ & $\begin{array}{l}\text { Kim (1993); Crossan, Lane e Whi- } \\
\text { te, (1999); Argyris, Schon (1996); } \\
\text { Maier, Prange e Rosenstiel (2001); } \\
\text { Weick e Westley (2004). }\end{array}$ \\
\hline $\begin{array}{l}\text { Aprendiza- } \\
\text { gem Grupal: } \\
\text { capacidade e } \\
\text { intercâmbio }\end{array}$ & $\begin{array}{l}\text { Trabalho de equipe e envolvimento de todos; } \\
\text { decisões e reflexões em grupo; compartilhamento } \\
\text { de conhecimento; troca e ajustes de experiências e } \\
\text { conhecimentos; grupos de projetos com múltiplos } \\
\text { atores; conhecimento e trabalho em grupo; intera- } \\
\text { ção multinível; orientação e feedback dos funcio- } \\
\text { nários; facilitadores da aprendizagem; aprendizado } \\
\text { mediante o planejamento; busca de informações } \\
\text { em diversos níveis; benchmarking e spillover; } \\
\text { ideias e melhorias. }\end{array}$ & $\begin{array}{l}\text { Huber (1991); Kim (1993); Dog- } \\
\text { son (1993); Defillippi e Ornstein } \\
\text { (2003); Choo (2006); Argyris } \\
\text { (1999); Pawlowsky (2001); Bido, } \\
\text { et al. (2010); Bispo e Mello } \\
\text { (2012); Songaglio, Godoi e Silva } \\
\text { (2013); Dias, Caldeiras e Godoy } \\
\text { (2012); Dias, Sauaia e Yoshizaki } \\
\text { (2013); Flaschberger, Gugglberger } \\
\text { e Dietscher (2013). }\end{array}$ \\
\hline
\end{tabular}


O Quadro 1 apresenta um panorama pelo qual se pode observar que a aprendizagem organizacional demanda, em seus diferentes níveis, dois aspectos principais: o trabalho em grupo e a busca de informações originada a partir de um questionamento da rotina de trabalho. Além disso, a interação multinível, associada às práticas de planejamento e benchmarking e o usufruto do conhecimento em excesso embutido em profissionais diversos do mercado (derramamento do conhecimento - spillover) contribuem para a "quebra" da rotina e inovações. A aprendizagem se configura, nesta pesquisa, de modo dinâmico e associada às práticas cotidianas da organização em questão. Os códigos do Quadro 1 permitem compreender como as dimensões de aprendizagem e suas respectivas subcategorias se manifestam na percepção dos entrevistados e do caso analisado.

\section{CONSIDERAÇÕES FINAIS}

Esta pesquisa contemplou o fenômeno da aprendizagem em suas dimensões individual, grupal e organizacional. $\mathrm{O}$ estudo ocorreu em uma empresa do setor Farmacêutico, e a análise do fenômeno foi feita a partir da percepção de seus gestores.

Diante disso, depreende-se que a aprendizagem organizacional pode ser vista como um processo, quando de seu ciclo contínuo, sendo constatado o processo de aquisição, compartilhamento, difusão e integração dos novos conhecimentos na rotina organizacional, e também como um resultado, uma vez que a organização é vista como um todo, e suas partes não funcionam sozinhas, como a alteração em algum departamento ou processo surte efeito no resultado final, sendo este de maior ou menor impacto, de acordo com o que foi mudado.

É válido apontar também que, sem o intercâmbio, isto é, sem a troca (relações interpessoais), não é possível que ocorra a aprendizagem organizacional, pois a aprendizagem envolve um processo contínuo por meio de pessoas, e estas, por sua vez, compartilham conhecimentos e experiências de acordo com o seu modelo mental. Mesmo que indivíduos tenham vivido conhecimentos idênticos, suas experiências são diferentes, uma vez que entra em cena a percepção do mundo de cada um, como também seus princípios e valores, fato que acrescenta grande diversidade à organização na formação dos grupos, pois acrescenta novos conhecimentos e possibilita novas práticas a partir dessas trocas, de modo que não é possível a ocorrência da aprendizagem organizacional sem intercâmbio. 
É perceptível a importância do indivíduo e sua participação nos grupos, buscando novos conhecimentos, mas também compartilhando suas experiências com os demais membros do grupo, pois esses momentos possibilitam novas visões, momentos únicos e cruciais para o intercâmbio de conhecimento. É relevante apontar que a organização não depende de uma única e específica pessoa para desenvolver a aprendizagem organizacional, pois cada pessoa contribui para esse processo de acordo com o período de tempo que esteve na empresa.

Assim, as organizações se tornam dependentes das pessoas para que ocorra a aprendizagem organizacional, mas não reféns de um único indivíduo. Por outro lado, as organizações devem proporcionar a possibilidade de troca por meio dos grupos em momentos formais, como treinamentos, reuniões e grupos de discussão, e também em ocasiões informais.

A análise dos dados evidenciou que vários momentos podem contribuir e levar à aprendizagem organizacional, podendo ser conscientes ou ainda inconscientes. Quando dos momentos conscientes, pode-se apontar as correções de erros e problemas, o planejamento para mudanças, e novas possibilidades que possam melhorar algum processo, ou ainda, melhorar e buscar melhores resultados.

As reuniões entre as próprias áreas e também com outros departamentos, configuram-se em troca de conhecimento, informações e experiências, além de que estas contribuem muito para o desenvolvimento das áreas (e da organização). Esses espaços incentivam a formação dos grupos, buscando a melhoria das práticas organizacionais, por meio da troca de conhecimento e experiências, no sentido de buscar a evolução da empresa. De acordo com os entrevistados, esses momentos são muito ricos, pois quando existe a abertura para esse compartilhamento, é possível conhecer visões diferenciadas e há a possibilidade de melhorias nos processos e tarefas realizadas.

Diante dessa situação, notou-se a relevância da aprendizagem individual quando se faz a troca com o líder ou diretamente com a equipe, introduzindo a aprendizagem grupal, buscando atingir o objetivo da empresa, gerando, assim, a aprendizagem organizacional, por meio de mudanças corretivas ou preventivas. Assim, a aprendizagem organizacional pode ser vista a partir da perspectiva sociológica, pois ocorre a partir da interação das pessoas, de acordo com as políticas organizacionais, diante da gestão de conflitos, como também pela questão do nível hierárquico e sua influência nas organizações que aprendem.

Desse modo, observa-se que a aprendizagem organizacional pode ser vista como um ciclo contínuo, que pode seguir o circuito simples, quando as ações de 
mudança não interferem nas estruturas e estratégias organizacionais, mas também pode ser, em determinado momento, circuito duplo, quando as mudanças exigem alterações nas estruturas e também nas estratégias, dependendo da situação.

Pode-se verificar o circuito simples no exemplo da mudança de ERP, mencionada pelo Entrevistado 2, pois se identificou a necessidade de mudança de sistema, que seguiu o ciclo de aprendizagem em sua aquisição, difusão, compartilhamento e integração do novo conhecimento na prática organizacional. Houve também um caso, relatado pelo Entrevistado, 5 sobre a mudança na quantidade de envio de remédios para amostras grátis. A mudança foi exigida, pois havia risco do envio de um comprimido a mais ou a menos na amostra grátis, e para isso, houve o entendimento de que era uma proposta viável (risco a ser assumido), inclusive pela própria gestão da empresa. Esse conhecimento foi compartilhado pelo gerente, que trouxe sua experiência de outra organização, e essa mudança contribuiu para a produtividade, mas exigiu uma mudança na estratégia organizacional, ou seja, constatou-se, no cenário investigado, que a perspectiva da aprendizagem organizacional se manifesta também por meio das práticas organizacionais: no caso estudado, próprias do segmento farmacêutico.

Esta pesquisa se limitou a uma empresa do segmento farmacêutico, bem como ao nível gerencial da organização, não se estendendo aos demais níveis hierárquicos. Nesse sentido, são válidos estudos futuros ampliando a amostra da pesquisa aos demais níveis hierárquicos e ainda em segmentos de mercado diversos. Vale ressaltar, também, outras possibilidades para pesquisas futuras que foram identificadas durante a construção deste trabalho, como o estudo da dimensão interorganizacional da aprendizagem, dimensão que foi percebida na organização estudada, porém, não investigada de maneira mais profunda, uma vez que não se tratava do objetivo desta pesquisa. Também vale a indicação para estudos sobre a gestão de competências como fator para administrar a aprendizagem organizacional, e ainda, estudos sobre as organizações como cultura, isto é, empresas com cultura de aprender.

\section{REFERÊNCIAS}

AMARO, R. A. A aprendizagem profissional em uma empresa de comunicação: um estudo à luz da aprendizagem informal. Revista de Administração da Unimep, v. 12, n. 2, p. 59-84, 2014. 
ANTONELLO, C. S.; GODOY, A. S. A encruzilhada da aprendizagem organizacional: uma visão paradigmática. Revista de Administração Contemporânea, v. 14, n. 2, p. 310-332, 2010.

ARGYRIS, C. D. On organizational learning. Oxford: Blackwell Publishers, 1999.

ARGYRIS, C. D.; SCHON, D. Organizational learning II: theory, method, and practice. Reading, MA: Addison Wesley, 1996.

BIDO, D. S. et al. Articulação entre as aprendizagens individual, grupal e organizacional: um estudo no ambiente industrial. Revista de Administração Mackenzie, São Paulo, v. 11, n. 2, p. 68-95, 2010.

BISPO, M. S.; MELLO, A. S. A miopia da aprendizagem coletiva nas organizações: existe uma lente para ela? Revista Gestão e Planejamento, Salvador, v. 12, n. 3 , p. 728-745, 2012.

BRUSONI, S.; ROSENKRANZ, N. A. Reading between the lines: learning as a process between organizational context and individuals' proclivities. European Management Journal, v. 32, n. 1, p. 147-154, 2014.

CALDEIRA, A.; GODOY, A. S. O processo de análise do ambiente e sua relação com a aprendizagem organizacional: um estudo de caso. REAd, v. 73, n. 3, p. 779, $812,2012$.

CHOO, C. W. A organização do conhecimento: como as organizações usam a informação para criar significado, construir conhecimento e tomar decisões. 2. ed. São Paulo: Senac, 2006.

CROSSAN, M.; LANE, H.; WHITE, R. An organizational learning framework: from intuition. Academy of Management Review, v. 24, n. 3, p. 522-537, 1999.

DAFT, R. L.; WEICK, K. E. Organizações como sistemas interpretativos: em busca de um modelo. In: CALDAS, M. P.; BERTERO, C. O. (Coord.). Teoria das Organizações. São Paulo: Atlas, 2007.

DEFILLIPPI, R.; ORNSTEIN, S. Psychological perspectives underlying theories of organizational learning. In: EASTERBY-SMITH, M.; LYLES, M. A. (Ed.). Handbook of organizational learning and knowledge management. London: Blackwell Publishing, 2003.

DENZIN, K. N.; LINCOLN, Y. S. O planejamento da pesquisa qualitativa: teorias e abordagens. Porto Alegre: Artmed, 2006. 432 p. 
DIAS, G. P. P.; SAUAIA, A. C. A.; YOSHIZAKI, H. T. Y. Estilos de aprendizagem Felder-Silverman e o aprendizado com jogos de empresa. Revista de

Administração de Empresas, v. 53, n. 5, p. 469-484, 2013.

DODGSON, M. Organizational learning: a review of some literatures.

Organization Studies, p. 375-394, 1993.

EBOLI, M. Educação Corporativa no Brasil: Mitos e Verdades. 2. ed. São Paulo: Gente, 2004.

FIOL, M.; LYLES, M. Organizational learning. Academy of Management Review, v. 10, n. 4, p. 803-813, 1985.

FLASCHBERGER, E.; GUGGLBERGER, L.; DIETSCHER, C. Learning in networks: individual teacher learning versus organizational learning in a regional health-promoting schools network. Health Educ. Res., v. 28, n. 6, p. 993-1003, 2013.

GIL, A. C. Como elaborar projetos de pesquisa. São Paulo: Atlas, 2010. 184 p.

HUBER, G. Organizational learning: the contributing processes and the literatures, Organization Science, v. 1-2, n. 1, p. 88-115, 1991.

KIM, D. H. The Link between Individual and Organizational Learning. Sloan Management Review, v. 35, n. 1, p. 37-50, 1993.

MAIER, G.; PRANGE, C.; ROSENSTIEL, V. L. Psychological perspectives of organizational learning. In: DIERKES, M. et al. (Org.). Organizational Learning and knowledge. New York: Oxford, 2001.

MERRIAN, S. B. Qualitative research and case study applications in education. San Francisco: Jossey-Bass, 1998.

MOSCARDINI, T. N.; KLEIN, A. Educação Corporativa e desenvolvimento de lideranças em empresas multisite. Revista de Administração Contemporânea, v. 19, n. 1, p. 84-106, 2015.

MOZZATO, A. R.; BITENCOURT, C. C. Understanding Interorganizational Learning Based on Social Spaces and Learning Episodes. Brazilian Business Review, v. 11, n. 3, p. 284-301, 2014.

NOGUEIRA, R. A.; ODELIUS, C. C. Desafios da Pesquisa em Aprendizagem Organizacional. Cadernos EBAPE.BR, v. 13, n. 1, p. 83-83, 2015. 
PAWLOWSKY, P. The treatment of organizational learning in management science. In: DIERKES, M. et al. (Org.). Organizational Learning and knowledge. New York: Oxford, 2001.

POWELL, W. W. Learning from collaboration: knowledge and networks in the biotechnology and pharmaceutical industries. California Management Review, v. 40, n. 3, p. 228-240, 1998.

RUAS, R. L.; ANTONELLO, C. S. Repensando os Referenciais Analíticos em Aprendizagem Organizacional: uma Alternativa para Análise Multidimensional. Revista de Administração Contemporânea, v. 7, n. 3, p. 203-212, 2003.

SONAGLIO, A. L. B.; GODOI, C. K.; SILVA, A. B. Estilos de Aprendizagem Experiencial e Aquisição de Habilidades: um Estudo com Discentes de Graduação em Administração em Instituições de Ensino Superior. Administração: Ensino e Pesquisa (RAEP), v. 14, p. 123-159, 2013.

TAKAHASHI, A. R. W.; FISCHER, A. L. Processos de aprendizagem organizacional no desenvolvimento de competências em instituições de ensino superior para a oferta de cursos superiores de tecnologia (CSTS). Revista de Administração Contemporânea, p. 818-835, 2010.

VERGARA, S. C. Métodos de coleta de dados no campo. São Paulo: Atlas, 2009.

VISSER, M. Gregory Bateson on deutero-learning and double bind: A brief conceptual history. Journal of the History of the Behavioral Sciences, v. 39, n. 3, p. 269-278, 2003.

WEICK, K.; WESTLEY, F. Aprendizagem Organizacional: confirmando um oximoro. In: CLEGG, S. R.; HARDY, C.; NORD, W. R. (Org.). Handbook de estudos organizacionais. São Paulo: Atlas, 2004.

\section{COMO CITAR ESTE ARTIGO:}

— SILVA, Elen Cristina Albuquerque da et al. Aprendizagem organizacional no setor $Z$ farmacêutico: uma análise multinível a partir da percepção dos gestores. RACE, Revista de Administração, Contabilidade e Economia, Joaçaba: Ed. Unoesc, v. 14, n. 3, p. 1091-1118, set./dez. 2015. Disponível em: < http://editora.unoesc. edu.br/index.php/race $>$. Acesso em: dia/mês/ano. 
Silva, E. C. A. da, Vieira, A. M., Kubo, E. K. de M., \& Bispo, M. de S. (2015). Aprendizagem organizacional no setor farmacêutico: uma análise multinível a

$\mathbb{1}$ partir da percepção dos gestores. RACE, Revista de Administração, Contabilidade e
$\gtrless$ Economia, 14(3), 1091-1118. Recuperado em dia/mês/ano, de http://editora.unoesc. edu.br/index.php/race 
